\title{
A Qualitative Study on Experiences of Patients with Esophageal Speech Training after Total Laryngectomy
}

\author{
Jing Geng1, Shuxin $\mathrm{Xi}^{2}{ }^{*}$, Peixia $\mathrm{Wu}^{2}$ \\ ${ }^{1}$ Department of Nursing, Medical School of Yangtze University, Jingzhou, China \\ ${ }^{2}$ Nursing Department, Eye and ENT Hospital of Fudan University, Shanghai, China \\ Email: gengjing89@163.com, *shuxinxi71@163.com
}

How to cite this paper: Geng, J., Xi, S.X. and Wu, P.X. (2021) A Qualitative Study on Experiences of Patients with Esophageal Speech Training after Total Laryngectomy. Yangtze Medicine, 5, 179-193. https://doi.org/10.4236/ym.2021.53018

Received: July 11, 2020

Accepted: September 14, 2021

Published: September 17, 2021

Copyright $\odot 2021$ by author(s) and Scientific Research Publishing Inc. This work is licensed under the Creative Commons Attribution International License (CC BY 4.0).

http://creativecommons.org/licenses/by/4.0/

\begin{abstract}
Background: Patients who had total laryngectomy not only have a pressure from the possible diagnosis of laryngeal cancer, but also suffer from unspeakable misery. To relieve the suffering, some patients choose esophageal speech training. However, most of the current researches focus solely on the results of the training with the negligence of the patients' mental health and their life experience during the training. A qualitative research is highly sensitive to patients' subjective feelings, and thus able to capture their subtle emotional changes. Objective: To explore deeply patients' real experiences of esophageal speech training after total laryngectomy and reveal the public their training experience of the unique and special group. Methods: In May 2018, researchers conducted a two-month field observation on and in-depth interviews with 15 patients who were on esophageal speech training after total laryngectomy in the esophageal speech training room of the Eye and ENT Hospital of Fudan University. The research applied phenomenological research method and Colaizzi Data Analysis. Results: The data analysis indicated four main themes: changes of mindset; showing positive attitudes and behaviors in training; shift in social relations; and arduous training process. Conclusion: The study has the finding that patients on esophageal speech training had negative emotions in the early stage of the training and dissatisfaction with its teaching. The repercussion of the surgery brought them changes of social relations, social bias and prejudice ensued. It is, therefore, urgent and crucial to give the speech trainees psychological counseling in the early stage to improve their qualities of life, to mobilize social support to incentivize their training, to optimize esophageal speech training teaching, and to regulate the management of the esophageal speech training environment.
\end{abstract}




\section{Keywords}

Laryngeal Cancer, Laryngectomy, Esophageal Speech, Qualitative Study

\section{Introduction}

Laryngeal cancer (LC) is a type of vicious tumor commonly seen in the head and neck; $40 \%$ of those confirmed cases are already in phase III or phase IV [1]. In 2012, data from GLOBOCAN [2] showed that the number of laryngeal cancer cases was approaching 160,000, among those were about 27,000 Chinese cases recorded in 32 tumor registries across China from 2003 to 2007. For terminal laryngeal cancer patients, especially in phase III or phase IV, and patients who failed radiotherapy or partial laryngectomy, total laryngectomy can play an indispensable role in its high cure rate. The survival rates for the following five years after the surgery are $60 \%$ to $90 \%$ [3] [4]. While total laryngectomy removes the tumor, it also impairs their inborn physiological function: speech. Patients after the surgery lose the ability to socialize or communicate with speech, which results in various social and psychological problems, and affects negatively the quality of their life. The necessity to build a new voice production method becomes pressing and beneficial. Currently, methods of the rehabilitation of voice production have two options: nonsurgical approach (electronic larynx, pneumatic artificial larynx, and esophageal speech) and surgical approach [5]. In 2012, German scholars carried out the investigation into patients' choice of the two options after total laryngectomy [6]. It showed that $83 \%$ of females and $57 \%$ of males chose esophageal voice, $17 \%$ of females and $29 \%$ males chose electronic larynx, and $17 \%$ of females and $20 \%$ of males chose the surgery for voice rehabilitation. The choice with the highest percentage, esophageal speech, is deemed the most economical and convenient for its flexibility and less pain or cost compared to the surgery [7]. Esophageal speech is thus the top choice for total laryngectomy patients (alaryngeal patients) in developing countries, especially in China. TEP (tracheo-esophageal phonation) is not common because of surgical complications and high cost [8].

In 1922, Seeman [9] first unraveled the myth of voice production by total laryngectomy patients. He discovered that cervical esophagus can function as a voice organ. Esophageal speech has been known to all since then. The introduction of esophageal speech has aroused huge interest in its research. Observations and surveys on, interviews with esophageal speech trainees have been conducted to explore various relevant issues, including esophageal speech mechanism, training methods, speech production assessment, complications, affecting factors of training results, and acoustic characteristics of esophageal speech [10] [11]. As early as 1950s, Bateman, et al. detailed on the mechanism of esophageal speech [12]. The training procedures for esophageal speech contain the formative stage of the ES and the stage of ES establishment and improvement. Eso- 
phageal speech training can be influenced by numerous factors, such as dysphagia, gastroesophageal reflux, psychological condition and attitudes toward teaching [13] [14].

However, the focus of present literature is mainly on the training (success rate, acoustic analysis), whereas seldom researches pay attention to the trainees' attitudes and experience of the training. In China, most of total laryngectomy patients choose esophageal speech training for speech rehabilitation, and train mainly in the professional sound lab. The majority of current researches, however, give little information on trainees' life experience during esophageal speech training.

Therefore, this paper uses phenomenological research to study the esophageal speech trainees after total laryngectomy from the Eye and ENT Hospital of Fudan University. As some trainees are unable to speak, writing, field observation and field notes are also adopted to obtain more detailed information. The study aims to unmask trainees' life experience and trainees' attitudes toward the whole training process. The profile of their training experience can help ES trainees gain more psychological and social support and help ES therapists more deeply understand trainees' feelings so as to better the individualized training program.

\section{Subjects and Method}

\subsection{Subjects}

Research subjects are ES trainees who had total laryngectomy from the Eye and ENT Hospital of Fudan University. The inclusion criteria for the subjects are as follows: patients receiving ES training after total laryngectomy; ES training takes place in the sound lab; trainees are mentally sound; trainees are able to communicate via written words or speech; trainees volunteer to participate in the research. Exclusion criteria are patients receiving radiotherapy or chemotherapy during ES training. Purposive sampling is used to select subjects who can provide the research with much relevant information. Data collection completes when no more new themes can be extracted from interviews (see detailed information in Table 1).

\subsection{Method}

The study applies phenomenological research methods of the qualitative approach, conducting field observations, field notes, and in-depth interviews by means of field study [15]. Interview tools contain semi-structured interview outline, Ji Yan Evaluating Grade [11], field recording sheet [16].

\subsection{Data Collection Procedure}

Before the study was carried out, the research proposal was reviewed and got the approval from Eye \& ENT Hospital Ethical Committee. The first step was that the consent form was showed to subject, the researchers explained the purpose of the study and asked the subjects signed their name on it. 
Table 1. General information of participants.

\begin{tabular}{|c|c|c|c|c|c|c|c|c|c|}
\hline Subjects & Age & Gender & $\begin{array}{l}\text { Communication } \\
\text { method }\end{array}$ & $\begin{array}{c}\text { Time since } \\
\text { esophageal speech }\end{array}$ & $\begin{array}{c}\text { Ji-yan } \\
\text { Evaluating Grade }\end{array}$ & Birthplace & $\begin{array}{l}\text { Education } \\
\text { level }\end{array}$ & $\begin{array}{l}\text { Marital } \\
\text { Status }\end{array}$ & $\begin{array}{c}\text { Main } \\
\text { caregiver }\end{array}$ \\
\hline S1 & 62 & M & $\mathrm{W}$ & 1 month & A0B0C1D1 (2) & Shanghai & MS & $\mathrm{Ma}$ & WAC \\
\hline S2 & 58 & M & $\mathrm{W}$ & 1 month & A0B0C0D0 (0) & Shanghai & Bachelor & $\mathrm{Ma}$ & Wife \\
\hline S3 & 67 & M & ELS (1.5 months) & 1.5 months & A0B0C0D1 (1) & Jiangsu & $\mathrm{N}$ & $\mathrm{W}$ & $\mathrm{C}$ \\
\hline S4 & 62 & M & $\mathrm{W}$ & 4 months & $\mathrm{A} 1 \mathrm{~B} 3 \mathrm{C} 2 \mathrm{D} 2(8)$ & Henan & PS & $\mathrm{Ma}$ & Wife \\
\hline S5 & 69 & M & $\mathrm{W}$ & 15 days & A0B0C1D1 (2) & Sichuan & MS & $\mathrm{Ma}$ & WAC \\
\hline S6 & 66 & M & $\mathrm{W}$ & 1 month & A1B1C1D1 (4) & Shanghai & MS & $\mathrm{Ma}$ & WAC \\
\hline S7 & 62 & M & $\mathrm{W}$ & 10 days & A0B0C0D0 (0) & Shanghai & MS & $\mathrm{D}$ & None \\
\hline S8 & 56 & M & ES & 2 years & $\mathrm{A} 3 \mathrm{~B} 3 \mathrm{C} 2 \mathrm{D} 3(11)$ & Anhui & JC & $\mathrm{Ma}$ & Wife \\
\hline S9 & 63 & M & ES & 3.5 years & $\mathrm{A} 3 \mathrm{~B} 4 \mathrm{C} 3 \mathrm{D} 3(13)$ & Jiangsu & PS & $\mathrm{Ma}$ & Wife \\
\hline S10 & 58 & M & ES & 11 years & A4B5C5D4 (18) & Shanghai & PS & $\mathrm{Ma}$ & Wife \\
\hline S11 & 62 & M & ELS (8 years) & 1.5 months & A1B1C1D1 (4) & Shanghai & JC & $\mathrm{Ma}$ & Wife \\
\hline S12 & 63 & M & ES & 5 years & A3B5C5D4 (17) & Shanghai & JC & $\mathrm{Ma}$ & Wife \\
\hline $\mathrm{S} 13$ & 65 & M & ES & 5 years & A5B5C5D5 (20) & Shanghai & PS & $\mathrm{D}$ & None \\
\hline S14 & 72 & M & $\mathrm{W}$ & 11 years & $\mathrm{A} 2 \mathrm{~B} 2 \mathrm{C} 2 \mathrm{D} 2(8)$ & Shanghai & PS & $\mathrm{Ma}$ & Wife \\
\hline S15 & 53 & M & ELS (5 years) & 2 months & A0B0C0D0 (0) & Shanghai & JC & $\mathrm{Ma}$ & Wife \\
\hline
\end{tabular}

Abbreviations: M, Male; W, Writing; ELS, Electrolaryngeal speech; ELS (1.5 months), communicate via electrolaryngeal speech for 1.5 months; ES, Esophageal speech; PS, Primary school; MS, Middle school; JC, Junior college; D, Divorced; Ma, Married; W, Widowed; C, Children; WAC, Wife and children. Ji-yan Grade: A, Continuous fluency level; B, Sound intensity level; C, Clearly understandable level; D, Voice acceptance level.

\section{In-depth Interviews}

In order not to interfere with patients' training activities, the researcher selected the suitable period and made an appointment with patients and conducted in-depth interviews. The quiet and tidy environment was selected to make the interview, usually in the small meeting room. Each interview took about 60 to 90 minutes. Recording and notebook were used to collect the data. All the interviews were sound recorded. For patients unable to speak, the researcher provided paper and pen for them to write. The interviewer was Mrs Geng, a master student and RN, and Mrs. Xi, the advisor, both of whom had got the qualitative study training and obtained the qualification to conduct a qualitative study. Interview tools contain semi-structured interview outline, Ji Yan Evaluating Grade. Interview questions are as follows: 1) What do you think of your ES training? 2) How do you feel during the training? 3) Do your feelings influence your training in any way? 4) How do you react to these feelings? 5) In what situation do you think you would be determined to do the training? Why? 6) In what situation do you think you would want to quit the training? Why? Ji Yan Evaluating Grade is a tool to get commonly used for ES level evaluation in China. It evaluates four parts: continuous fluency level, sound intensity level, clearly understandable level, voice acceptance level. And every part is divided into 5 grades ( 0 - 5 points). Then sum up all points: Very poor ES level (1 - 4 
points), poor ES level (5 - 8 points), medium ES level (9 - 12 points), good ES level (13 - 16 points), excellent ES level (17 - 20 points).

\section{Field Observations and Field Notes}

The researcher had a 7-month internship in the ENT department of the hospital. The field observation focused on speech therapy of patients who had total laryngectomy. The researcher had a two-week learning experience in the sound lab as a nurse for advanced learning. The learning included esophageal speech theory, its training methods, instructions, etc. The researcher also tried to communicate frequently with the patients so as to reduce the unfamiliarity with each other. With the guidance of esophageal speech therapist, the researcher recorded the observations. The field observation lasted from $5^{\text {th }}$ of May to $25^{\text {th }}$ of July, 2018. Descriptive observation on their daily activities was done during the training in the first week. After that was a two-month focus observations and interviews. A few representative patients were chosen as subjects using a purposive sampling method. The researcher was fully involved in the patients' life to observe their social activities in a real-life context. The last stage was a one-week selective observation. The researcher returned to the site and resumed participant observations and interviews. The data collected at this stage were compared to the previous ones to confirm if they were in agreement and if the files were representative. Throughout the field study, the researcher used field recording sheet (Table 2) to record all observations. This recording took place at inconspicuous locations to avoid possible aversion from patients or interference with events.

\subsection{Data Analysis}

Data analysis was conducted by the main researchers through Colaizzi approach [17]. First, descriptions of all participants were read repeatedly to feel sympathy on them. Second, the protocols were referred to and important phrases were extracted. Third, the meaning or concept of every important phrase was shaped which was formed into the title of concepts by researcher. Fourth, a set of concepts were organized into thematic categories. Fifth, the findings were integrated into a comprehensive description of the phenomenon. Comprehensive description of the phenomenon was formulated in the form of an explicit statement. In the last stage, the results were returned to participants to verify and their ideas were taken regarding the findings. Finally, four themes were identified.

Table 2. Field recording sheet.

\begin{tabular}{|c|c|c|c|}
\hline \multicolumn{4}{|c|}{ Recording time: } \\
\hline Participant & & Researcher & Memo \\
\hline $\begin{array}{l}\text { Behavior } \\
\text { (physiological reaction, deportment, } \\
\text { human interaction, space distance, } \\
\text { character relationship) in details }\end{array}$ & $\begin{array}{l}\text { Emotion } \\
\text { development and } \\
\text { progression of } \\
\text { emotion in details }\end{array}$ & $\begin{array}{c}\text { impression, } \\
\text { feeling, } \\
\text { thought }\end{array}$ & \\
\hline
\end{tabular}




\section{Results}

Totally, 15 patients (Table 1) were interviewed and observed until the data was considered getting saturation. The core construct, patients' views on esophageal speech training, involved four central themes: changes of mindset, Showing positive attitudes and behaviors in training, shift in social relations, and arduous training process. The themes, sub-topics and observations are listed in Table 3.

The following are more details about the sub-topics and themes.

\section{Theme 1: Changes of mindset}

Table 3. Esophageal speech trainees' training experience.

\begin{tabular}{|c|c|c|}
\hline Theme & Sub-topics & Observations \\
\hline \multirow{4}{*}{ Changes of mindset } & Pain & $\begin{array}{l}\text { Inability to speak; loss of loved jobs; } \\
\text { a cancer patient }\end{array}$ \\
\hline & Humiliation & Bad appearance; cough with sputum \\
\hline & Helplessness & $\begin{array}{l}\text { Feeling like a mute at the beginning; } \\
\text { esophageal speech sounds like a robot; } \\
\text { inability to argue but to swallow an insult }\end{array}$ \\
\hline & Optimism & $\begin{array}{l}\text { Taking initiative to try new things; } \\
\text { face life with a positive attitude }\end{array}$ \\
\hline \multirow{3}{*}{$\begin{array}{l}\text { Showing positive } \\
\text { attitudes and } \\
\text { behaviors in training }\end{array}$} & Mutual support & $\begin{array}{l}\text { Model and communicate in the sound } \\
\text { lab; create a Wechat and QQ group }\end{array}$ \\
\hline & Voluntary training & $\begin{array}{l}\text { Stick to the training plan themselves; under } \\
\text { the guidance of trainers, patients practice } \\
\text { esophageal speech in their preferred ways }\end{array}$ \\
\hline & "Resocialization" & $\begin{array}{l}\text { After successfully acquiring ES, } \\
\text { patients return back to their jobs, } \\
\text { gatherings, and other social activities }\end{array}$ \\
\hline \multirow{4}{*}{$\begin{array}{l}\text { Shift in } \\
\text { social relations }\end{array}$} & Alienation & $\begin{array}{l}\text { Inability to speak; friends encourage less talk } \\
\text { for fear of fatigue; embarrassment about } \\
\text { special treatment from friends }\end{array}$ \\
\hline & $\begin{array}{l}\text { Social interaction } \\
\text { limitations }\end{array}$ & $\begin{array}{l}\text { Low volume of ES causes difficulty in } \\
\text { arguing when irritated. Emotionless } \\
\text { speech mistaken for rudeness or hostility }\end{array}$ \\
\hline & Discrimination & $\begin{array}{l}\text { Patients are called mutes and treated } \\
\text { with less patience. Getting trash talk } \\
\text { and unfair distance from other people }\end{array}$ \\
\hline & New connections & $\begin{array}{l}\text { Patients bind together to gather, travel, } \\
\text { and socialize }\end{array}$ \\
\hline \multirow{4}{*}{$\begin{array}{l}\text { Arduous } \\
\text { training process }\end{array}$} & Physical discomfort & Stomach flatulence and increased nasal mucus \\
\hline & Negative life events & Long commute; forced resignation; lonely life \\
\hline & $\begin{array}{l}\text { Various assisting } \\
\text { methods }\end{array}$ & $\begin{array}{l}\text { Applying various assisting methods for voice } \\
\text { production to increase communication with } \\
\text { speech }\end{array}$ \\
\hline & Dissatisfaction & Feeling unsatisfied with ES training program \\
\hline
\end{tabular}


Pain The facts that patients lose speech after total laryngectomy, that they are diagnosed with cancer, and that the initial training results are not satisfactory can easily cause trainees painful feelings. Here is what S8 recounted:

"I was just like the other patients at the beginning, having unspeakable pain. People like us have two kinds of burdens. One is the psychological burden of having the disease. The other is that we cannot communicate with others."

Humiliation A permanent laryngostomic fistula appears after the total laryngectomy and affects directly one's appearance. Moreover, cold air and tiny items, once go through the larynx, cause patients a sort of staccato coughing. This brings patients humiliation, especially in a public context.

S7: "It (laryngostomic fistula) is so ugly. It also causes chronic coughing. It's useless (head shaking); we cannot talk or communicate."

S1: "I zip my collar up very high every day for fear of exposing the laryngostomic fistula. I am the most afraid of being called a mute."

Even though the laryngostomic fistulas of patients who have successfully acquired esophageal speech are covered or beautified, the problem of coughing with mucus persists. On a public occasion, this problem still incurs embarrassment. S10, a successful ES learner, shares his experience:

"I will start off early in the morning. I leave home before 7am every morning when there are not many people on the metro. Otherwise, people would also stare at you when it (laryngostomic fistula) causes cough. And I take the bus only when there are fewer people. I have been wearing this jade pendent since three years ago after the surgery. I wear it all the time."

Helplessness Even a successful ES learner still needs frequent practice. However, many people, including a number of their friends, exclude them the opportunities to talk. Patients feel that they cannot do anything about it. S12 complained about this.

"People don't have much patience to listen to us talking. When talking to (near) strangers, we are asked not to continue with the reason that they cannot hear clearly or understand. Rude people justlabel us mutes, which is very hurtful. Polite people would encourage us not to talk much to tire ourselves. But communication is a must between people; and communication requires talk. If you are asked not to talk, how will you feel?'

In a noisy situation, it becomes more difficult for patients to talk due to the low volume of esophageal speech. Even successful ES learners still have limitations on communication; they can easily feel helpless when put in an argument or bicker.

S12 recalled, "I was driving a scooter one day when suddenly a car dashed out from a corner. We were both very scared. Nevertheless, that driver cursed and blamed me for this. I had no other alternatives but to give him a stare and then left since he couldn't understand me. Things like this happen often, and I have no means to argue, let alone to quarrel."

Optimism In the process of ES training, patients' attitudes toward life change while they are regaining their verbal ability. Some patients hold a hedonistic 
mindset, "Carpe Diem", while alive, be positive and curious. Never give up passion and pursuit of a good life. What S12 said epitomizes the ideal:

"Any acquaintance is prearranged in our destiny. Heaven-bestowed destiny allows us the patients to meet and gather. As I have this cancer, every day is bestowed. We should not only live, but live it well and happily. I have tried to be open-minded all along. Otherwise, life would be difficult. People like us are relatively more optimistic."

\section{Theme 2: Showing positive attitudes and behaviors in training}

Mutual support Patients in training have shared experiences and empathetic feelings. The commonalities bind them together naturally. Patients would like to communicate with and encourage each other whenever questions of either life or training occur. They even create their own Wechat group and QQ group for more efficient and convenient communication.

S10 said, "All of us ten patients use Wechat, QQ, and computers. I only knew how to use them not long ago when we learned together. I first learned about texting, then Wechat. Even the 72-year-old Mr. Cai uses Wechat, how is that? We have our own Wechat group. We would like to share and discuss in the group all sorts of things in the group."

Voluntary training Each patient has a strong desire to be able to speak again. As what S3 said, "I have never thought of giving up. I must speak. I must speak!"

Although patients' training progress varies, successful ES learners have the comment that if determination made and efforts paid, ES training will be a success. S9, another ES speaker, narrated his ES learning experience:

"After the surgery, I told my wife to go to work without worrying about me. I then practiced ES in the mornings and played Mahjong in the afternoons. At the beginning, I drank about 40 bottles of Sprite whose packaging size was 2 liters. At that time, there was a convenience store right by where I lived. My family members helped me buy a cart of Sprite in advance for me to get hiccups and practice ES. I didn't know how to make the voice until six months later. My trainer told me that some people could even do it within one or two months. So if you really want to speak, you just have to keep practicing."

"Resocialization" Trainees choose to go back to work after successfully acquiring esophageal speech. S9 is one of them.

"Now that I learn how to speak via ES, I can talk to people without difficulty. I found a job to be a janitor. I have two night shifts and two daytime shifts every week. I can get some sleep on the night shifts. The job is not tiring but keeps me busy, which is good. If I just stayed at home idling, I would feel I was quarantined."

Like S9, there are many other ES speakers who decide to get involved in social life. They would like to participate in gatherings and social activities, in hopes of letting people aware that people like them do exist. When these ES speakers can give others assistance, they feel very happy. S12's way of achieving this is through philanthropy. 
"Each of us donates 120 RMB to charitable organizations in Shanghai every year. Our cancer rehabilitation center helps us transfer the money to the organizations. Charitable organizations express their appreciation by giving some money back to our center and organizing us a short-distance trip."

\section{Theme 3: Shift in social relations}

Alienation For patients who have not acquired ES, they prefer only to listen. Sometimes they write down what they want to say to communicate. However, they eventually choose to estrange due to the communicative hindrance. S3 lamented his situation:

"Before the surgery, my buddies and I would play cards or chess frequently. But I now choose not to go. Whatever I say doesn't make sense of them, though I have the electronic larynx. What makes it worse is that I don't write."

Successful ES learners are not always away from a similar situation. More often than not, friends would sit square and become very attentive every time ES speakers talk. The special treatment makes patients feel uneasy and thus choose to estrange from their friends. S12 explained this situation with an example.

"When I meet with friends, I don't talk much as I know my own speech defects. When I do talk, friends would sit up and stare at me to listen. I know that they are being polite. But their reactions make me embarrassed, and I choose to be silent or even quit going to such gathering."

Discrimination In their everyday life, patents are no strangers to supercilious look or shafts of ridicule from people. S1 had a sad story.

"I really shudder when people call me a mute. Once, I was queuing in a hospital. Suddenly, a guy cut in line in front of me and called me a mute. I felt so irritated that I whacked him."

Social interaction limitations Characteristics of esophageal speech, such as low sound quality, low volume and austere facial expressions, obstruct patients from normal communications as these features are not well recognized by people and thus easily lead to misunderstandings. Patients know their own speech defects. They attempt to reduce conflicts and confrontations with other people by swallowing insults silently. S10, an ES speaker, illustrated his situation.

"I think we should not look at people's faces even when we are able to talk again. When we speak, we have to force our voice out. That would make us look stern and austere. People would think we are arguing with them. This situation repeats often in a restaurant when we have dinner with friends. Everything is fine when the topics are light and easy. But when we do have different views, people would complain about my 'bad manners', telling from my facial expression. They don't know that my look is always like this, this is how I talk via ES. The more we counter, the less clearly we can speak. Eventually, we just quit talk. How frustrating!"

New connections Through esophageal speech training, patients' verbal ability rebuilds, so do their social connections, though gradually. They start afresh, traveling with friends, joining parities, and attending social activities. Here are what S10 and S12 say about this, respectively. 
"My old friends and I are kind of drifting apart. We the patients have more gatherings as we understand each other better and give each other more patience. The cancer rehabilitation center organizes activities for us every month. We just eat and chat. We all enjoy this. They also provide two trips every year. I, along with about a dozen others, meet on Fridays. Everyone shows eagerness to join."

"When we patients talk to each other, we respect each other and give mutual patience as we all speak pretty slowly. If I don't catch what s/he says, I ask for pardon and repeat. We all know that we would one day be in a similar situation and hope for the same treatment. My speech is alright, but it is still discontinuous sometimes. I do not have any other means. I can only say that much in one breath."

\section{Theme 4: Arduous training process}

Physical discomfort The learning of the basic sounds of esophageal speech easily causes regurgitation. Some patients even have vertigo due to the high-frequency practice, but the dizziness would dissipate with the progression of training. When asked about his case, S12 said "The first year (of training) was the most difficult. I was trying to prolong the hiccups by shouting till I felt dizzy. I then took a rest and proceeded. The result came gradually."

Other patients had grumbled stomach while practicing esophageal speech. Although quite normal, it does affect their social life. S12 was one of them. Here is exactly what he said about his situation.

"Unlike me, they don't have the noise coming from their stomach. They joked that I had been carrying a tube for six years. The noise actually comes from the air in the stomach bouncing back and forth, but it is embarrassing in conversation when the noise comes."

Negative life events Laryngocarcinoma patients have to face miscellaneous repercussions, especially after total laryngectomy. Long distance, forced resignation from jobs, negative impact from social, and loneliness would block their ES training. Depression likes to reside in these patients who feel that life is too hard. S3 echoed these difficulties.

"I live in a village in Kunshan. I have to leave at 6 in the morning in order not to be late for the 9 o' clock training. The commute consists of one-hour bus ride and one-hour metro ride. The round trip is more than 4 hours. It is too far, sometimes I really don't want to come for the training."

A former esophageal speech trainer, S2 had to give up his job because of laryngocarcinoma at the age of 58. He shook his head, saying, "It's impossible to get back now. Making hiccups is hard; I can't get it... The trainers here are very professional. I come for their guidance every week, and then go home to keep practicing. It's not easy, so I must keep confidence."

Various assisting methods In order to expedite the learning of the basic sounds of ES, patients try various auxiliary methods (e.g. Drinking tea, soda, or eating kumquat fruits). These methods do help them produce hiccups easier and faster. $\mathrm{S} 8$ is one of the examples. 
"Initially I also drank Sprite, but it didn't work so well for me. I then chose to drink tea. I stayed at home practicing all day, trying to master the technique. You have to learn how to move the air in the stomach out quickly."

The learning of esophageal speech requires long-term hard work. Boredom is unavoidable. Some patients choose karaoke to add fun and momentum to their practice. S10 shared his experience, “Although we didn't know how to sing, we still kept going to karaoke for a year. All we did was to shout. Overtime, the results showed. Going to karaoke is more interesting than only making hiccups."

Dissatisfaction During the field observation period, researchers found that the training procedure in the sound lab went like this: The trainers introduced esophageal speech, its goal, training methods, and training instructions. A training contract would be signed right after. The trainees learn how to form the basic ES sounds; $f$ Trainees demonstrate esophageal speech. Patients, however, are not all satisfied with the training procedure. They complained that the training was not worth the money the paid. Most of training activities were done only by patients themselves. But some patients held different views on this. S8 said, "the ES trainer just explains and demonstrates for us. And the main training is still depending on ourselves. Trainers provide us with a good platform where patients gather together to practice. Moreover, we can get some reimbursement since we get the treatment in a public hospital."

\section{Discussion}

The first discovery of esophageal speech trainees' life experience and trainees' attitudes toward the training process by phenomenological research is that patients had negative emotions in the early stage of the training and received social bias and prejudice ensued. The findings could help medical staff and the public understand ES trainees deeply for more psychological and social support.

\subsection{Esophageal Speech Training Helps to Add Positivity}

The study finds that negative feelings, sense of shame, and pain are common among trainees, which are consistent with the findings by Mary in 2001 [18]. Among the 56 patients who had total laryngectomy, Mary found that $66 \%$ felt the permanent laryngostomic fistula unacceptable and 57\% couldn't bear the loss of speech. The dramatic changes incurred many psychological issues. Also, $30 \%$ of those who lost speech and 32\% who had impaired appearances had a strong sense of shame. However, the progression of ES training, while recovering their verbal ability, helps them change their mindset and face their life with optimism. Qing Chen [19] surveyed that collective esophageal speech training improved self-efficacy and confidence of laryngectomees. The success in mastering esophageal speech did not depend on whether the patients were trained individually or collectively, but the motivation of the patients [20].

Previous researchers have evidence that psychological factors most affect their life quality of patients after total laryngectomy [21]. George L. Engel's "Grief 
Theory" listed five stages for individuals undergoing grief: shock and disbelief, developing awareness, restitution, resolution of the loss, and recovery [22]. The subjects in this study had all passed the stage of shock and disbelief. During the stage of developing awareness, subjects had complex feelings. These feelings stemmed from their loss of speech, the sense of shame and frustration from permanent laryngostomic fistulas, and sense of helplessness after losing their verbal ability. The last three stages witnessed patients' progress: they started to seek for medical assistance and rationally coped with negative feelings; they tried to change the status quo of being silenced via attending ES training sessions. The sound lab has functioned as not only a training facility for patients, but also a location for them to communicate with and encourage each other. Overtime, patients started to make new friends and set up their own social circles, which ameliorated their life attitudes. Patients became active in trying different things and optimistic about their future life.

\subsection{ES training Helps Patients Establish New Social Circles}

Total laryngectomy causes speech impairment, troubled mental state, and reduced ability in social interactions. The physical recovery after total laryngectomy cannot offset the accruing changes in their life styles, family and social relations [23]. Babin et al. [24] suggested that voice deprivation was a limiting factor in social relationships, tending to push individuals into social withdrawal. Researchers in this study also found high frequency phrases (e.g. less communication; no more contact) by patients from the interviews to describe their relationship with their previous friends. Their old friends are drifting apart: their old-time chess friends, workmates, and classmates are gradually distancing from them. Peer support can help cancer patients and relatives cope in and outside the hospital in several ways [25]. Laryngectomees experience a sense of belonging when meeting other laryngectomees, with the same willingness to learn esophageal speech, with the same teacher [19]. The belongingness strengthened their confidence and gradually eliminated the negative feelings. Actually, the laryngectomee had a small circle of friends; but along with esophageal speech training, they identified like-minded people with common feelings and shared experience. Knowing the difficulty and abnormality of esophageal speech, they all listened to each other patiently and showed their respect. When words were not understood, clarification and repetition would be requested. The patients had also joined in the Cancer Recovery Association and participated in gathering, tourism, singing performance, raising funds, and other social activities. Some patients have considered this group as an essential part of their life. The esophageal speech closely resembled a normal voice, and was easily accepted by others

\section{Limitations and Suggestions}

In the present study, all participants were male. Given the location of the ES 
Dept, most participants came from Shanghai. However, these limitations provide direction for future researches, which might include larger and more diverse samples like women patients on esophageal speech training after total laryngectomy. Although the interviewees agreed to be recorded, sporadic intelligibility of speeches by ES speaker and patients with electronic larynx caused loss of some data. Additionally, part of subject only could communicate with writing, this situation may influence the deep and elaborated expression of the subject. Further studies are needed to focus on patients with mastered esophageal speech successfully for especially testing changes in social relations.

\section{Conclusions and Implications}

The findings of the study describe patients' views and experience on psycho-social parts of esophageal speech training after total laryngectomy. The findings reflected that those patients exhibiting poor speech intelligibility and having neglected experience are more likely to be emotionally distressed and frustrated in the primary stage of esophageal speech training. Nonetheless, with training time getting longer, patients can gain speech ability to some extent and become more positive toward the training in spite of tough practicing. During the training period, patients get great psychological support from their family. With that support, some of patients are able to return to work and restore their social relationship successfully with socially accepted pronunciation. However, as some participants described, their social relationships have changed, e.g., the estranged friends, being discriminated or ignored. They also reported dissatisfaction with speech teaching.

The finding can be used to improve the quality of care and teaching for patients with esophageal speech training in many ways. Firstly, given that the patients have more distressful feelings with poor speech intelligibility at an early stage, the speech therapist plays an important role when the training starts. It would benefit the patients if speech therapists can pay close attention to their emotional state, empower and encourage them to overcome negative emotions. Emotional support should be seen as an important part of the whole training. Secondly, a proposal for more rehabilitation programs for esophageal speakers is presented, by which the patients are easier to communicate and coordinate with each other. Furthermore, enhancing public awareness of esophageal speech through the media will be helpful to improve patients' social intercourse. Finally, the study demonstrated that the patients were not satisfied with teaching contents and environment. Strategies once implemented can help to improve the situation, which is to design more specific courses, implement more group activities, and get more timely feedback.

\section{Acknowledgements}

The study was funded by the Research Funding Program, School of Nursing, Fudan University (FNF201316). This work was also supported by the Eye \& ENT Hospital of Fudan University. The authors would like to acknowledge all the 
participants and colleagues who supported this study.

\section{Conflicts of Interest}

The authors have no conflicts of interest to declare pertaining to this article.

\section{References}

[1] Pfister, D.G., Laurie, S.A., Weinstein, G.S., et al. (2006) American Society of Clinical Oncology Clinical Practice Guideline for the Use of Larynx-Preservation Strategies in the Treatment of Laryngeal Cancer. Journal of Clinical Oncology, 24, 3693-3704. https://doi.org/10.1200/JCO.2006.07.4559

[2] World Health Organization (2012) International Agency for Research on Cancer. Globocan 2012: Estimated Cancer Incidence and Mortality and Prevalence Worldwide in 2012. http://globocan.iarc.fr/

[3] Ji, W., Du, Q., Guan, C., et al. (2004) Survival Analysis of 1115 Patients with Laryngeal Carcinoma. Chinese Journal of Otorhinolaryngology, 39, 17-19.

[4] Lennie, T.A., Christman, S.K. and Jadack, R.A. (2001) Educational Needs and Altered Eating Habits Following a Total Laryngectomy. Oncology Nursing Forum, 28, 667-674.

[5] Chen, H.C., Kim Evans, K.F., Salgado, C.J., et al. (2010) Methods of Voice Reconstruction. Seminar in Plastic Surgery, 24, 227-231.

https://doi.org/10.1055/s-0030-1255340

[6] Keszte, J., Wollbruck, D., Meyer, A., et al. (2012) The Role of Sex in Voice Restoration and Emotional Functioning after Laryngectomy. Laryngorhinootologie, 91, 240-246. https://doi.org/10.1055/s-0031-1301305

[7] Loscos, A. and Bonada, J. (2006) Esophageal Voice Enhancement by Modeling Radiated Pulses in Frequency Domain. San Francisco, CA.

[8] Zeng, Z., Su, S. and Wang, Z.-L. (2016) Reconstruction of Laryngeal Function after Total Laryngectomy. Chinese Journal of Ophthalmology and Otorhinolaryngology, 16, 53-56.

[9] Seeman, M. (1922) Speech and Voice without Larynx. Casopis Lékaru Ceských, 41, 369-372.

[10] Doi, H., Nakamura, K. and Toda, T. (2010) Statistical Approach to Enhancing Esophageal Speech Based on Gaussian Mixture Models. 2010 IEEE International Conference on Acoustics, Speech and Signal Processing, Dallas, 14-19 March 2010, 4250-4253. https://doi.org/10.1109/ICASSP.2010.5495676

[11] Han, D. (2003) Laryngeal Cancer-Treatment and Rehabilitation. People's Medical Publishing House, Beijing, 54.

[12] Bateman, G.H. and Dornhorst, A.C. (1952) Oesophageal Speech. British Medical Journal, 2, 1177-1178. https://doi.org/10.1136/bmj.2.4795.1177

[13] Natvig, K. (1983) Laryngectomees in Norway. Study No. 3: Pre- and Postoperative Factors of Significance to Esophageal Speech Acquisition. The Journal of Otolaryngology, 12, 322-328.

[14] Cocuzza, S., Bonfiglio, M., Chiaramonte, R., et al. (2012) Gastroesophageal Reflux Disease and Postlaryngectomy Tracheoesophageal Fistula. European Archives of Oto-Rhino-Laryngology, 269, 1483-1488.

https://doi.org/10.1007/s00405-012-1938-2

[15] Kruger, E., Tennant, M. and George, R. (2012) Qualitative Research and Dental 
Public Health. Indian Journal of Dental Research, 23, 92-96. https://doi.org/10.4103/0970-9290.99047

[16] Li, X. and She, S. (2006) Qualitative Research Method. Wuhan University Press, Wuhan, 162.

[17] Colaizzi, P. (1978) Psychological Research as the Phenomenologist Views It. Oxford University Press, New York, 48-71.

[18] Nalbadian, M., Nikolaou, A., Nikolaidis, V., et al. (2001) Factors Influencing Quality of Life in Laryngectomized Patients. European Archives of Oto-Rhino-Laryngology, 258, 336-340. https://doi.org/10.1007/s004050100376

[19] Chen, Q., Luo, J., Li, J.P., Jian, D.N., Yuchi, Y., Ruan, H.X., et al. (2019) Influence of Collective Esophageal Speech Training on Self-Efficacy in Chinese Laryngectomees: A Pretest-Posttest Group Study. Current Medical Science, 39, 810-815. https://doi.org/10.1007/s11596-019-2109-0

[20] Kresic, S., Veselinovic, M., Mumovic, G. and Mitrovic, S.M. (2015) Possible Factors of Success in Teaching Esophageal Speech. Medicinski Pregled, 68, 5-9. https://doi.org/10.2298/MPNS1502005K

[21] Singer, S., Fuchs, M., Dietz, A., et al. (2007) Relevance of Psychosocial Factors in Speech Rehabilitation after Laryngectomy. Laryngorhinootologie, 86, 867-874. https://doi.org/10.1055/s-2007-966843

[22] Li, X. (2003) Introduction to Nursing. 2nd Edition, Hunan Science and Technology Press, Changsha.

[23] Tong, Y., Zhang, C. and Yao, L. (2008) Experience of Patients after Total Laryngectomy for Laryngeal Cancer. Chinese Journal of Nursing, No. 8, 677-680.

[24] Babin, E., Beynier, D., Le Gall, D. and Hitier, M. (2009) Psychosocial Quality of Life in Patients after Total Laryngectomy. Revue de Laryngologie-Otologie-Rhinologie (Bord), 130, 29-34.

[25] Skirbekk, H., Korsvold, L. and Finset, A. (2018) To Support and to Be Supported. A Qualitative Study of Peer Support Centres in Cancer Care in Norway. Patient Education and Counseling, 101, 711-716. https://doi.org/10.1016/j.pec.2017.11.013 